Jan D. Lüttringhaus

\title{
Grenzüberschreitender Diskriminierungsschutz - Das internationale Privatrecht der Antidiskriminierung
}

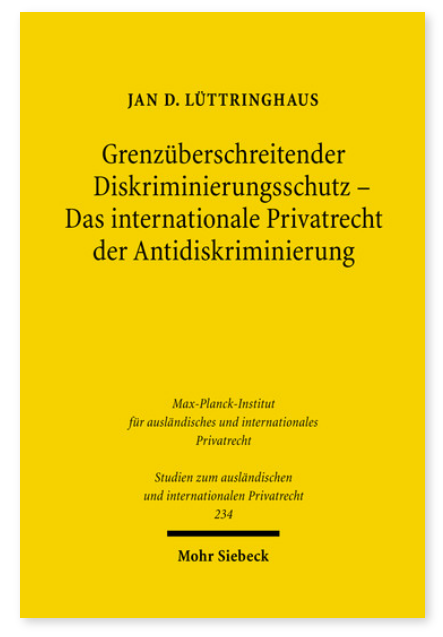

2010. XXV, 449 Seiten. StudIPR 234

ISBN 978-3-16-151419-7

DOI 10.1628/978-3-16-151419-7

eBook PDF 94,00€

ISBN 978-3-16-150244-6

fadengeheftete Broschur 94,00€
Diskriminierungen treten besonders häufig auf, wenn Verträge über Staatsgrenzen hinweg geschlossen werden. Gleichbehandlungsvorstellungen europäischer Prägung müssen hier grundsätzlich umso stärker zurückstehen, je intensiver ein fremder Kulturkreis betroffen und das Rechtsverhältnis dort verwurzelt ist. Doch wie ist das räumlich-territorial anwendbare Antidiskriminierungsrecht im Einzelnen zu bestimmen? Jan D. Lüttringhaus beantwortet diese Frage anhand der zunehmend vergemeinschafteten Kollisionsnormen des IPR. Er untersucht dabei neben dem internationalen Schuld- und insbesondere Arbeits- und Versicherungsvertragsrecht auch das internationale Verbands- und Gesellschaftsrecht. Da einige EG-Mitgliedstaaten Benachteiligungen zusätzlich mithilfe des Straf- bzw. Verwaltungsrechts sanktionieren, geht der Autor auch auf die Konflikte ein, welche sich aus der Kombination hoheitlicher und privatrechtlicher Diskriminierungsschutzkonzepte in Sachverhalten mit Auslandsbezug ergeben.

Jan D. Lüttringhaus Geboren 1980; Studium der Rechtswissenschaft in Passau, Aix-en-Provence, Bonn, New York; 2009 Promotion; 2011 Otto-Hahn-Medaille der Max-Planck-Gesellschaft; 2017 Habilitation; 2007-09 Assistent sowie seit 2011 Referent am Max-Planck-Institut für ausländisches und internationales Privatrecht und Lehrbeauftragter an der Universität Hamburg.

Jetzt bestellen:

https://mohrsiebeck.com/buch/grenzueberschreitender-diskriminierungsschutz-das-internationale-privatrecht-derantidiskriminierung-9783161514197?no_cache=1

order@mohrsiebeck.com

Telefon: +49 (0)7071-923-17

Telefax: $+49(0) 7071-51104$ 